\title{
Single-parenting influence on child's academic performances at MutareJunior School, Zimbabwe
}

Tendai Caithness Muhle*, Department of Psychology, Julius Nyerere School of Social Sciences, Great Zimbabwe University, P. Bag 1235, Masvingo, Zimbabwe

\section{Suggested Citation:}

Muhle, T. C. (2020). Single-parenting influence on child's academic performances at Mutare Junior School, Zimbabwe. Global Journal of Psychology Research: New Trends and Issues. 10(2), 140-153. https://doi.org/10.18844/gjpr.v10i2.4835

Received from July 14, 2020; revised August 20, 2020; accepted September 26, 2020.

Selection and peer review under responsibility of Prof. Dr. Tulay Bozkurt, Istanbul Kultur University, Turkey. ${ }^{\circ} 2020$ Birlesik Dunya Yenilik Arastirma ve Yayincilik Merkezi. All rights reserved.

\begin{abstract}
The economic hardship that has plagued Zimbabwe has led to a shift from the traditionally intact family to a singleparenthood family. Many factors lead to single parenthood including divorce, separation of all kinds and deaths. Single parenthood negatively impacts on students' academic development. The researcher explored influences of SingleParenthood to Academic-Performances (AP) of Grade 6 and 7 students at Mutare Junior School in the Manical and Region of Zimbabwe. The researcher used 'cross-sectional study design' to collect data using criterion attainment tests, 'the Wide Range Achievement Test Level 1 (WRAT-1)' on 80 students under controlled situations having 40 Single-Parent-Homes (SPH)and 40Double-Parent-Homes (DPH)students. School-established examinations complemented data from theWRAT-1 outcome. Tables and ' $T$-tests' were used for analysis of data. Results revealed children from DPH performing statistically better on the criterion test than those from SPH $(t=-4.928$, significance value 0.05$)$. The results also indicated males performing better than females both from SPH on the criterion test ( $t=-4.196$, significance value 0.05$)$. In future, research should focus on different single-parent homes to AP.
\end{abstract}

Keywords: Academic performance, influence, pupils, school, single parenting.

\footnotetext{
* ADDRESS FOR CORRESPONDENCE: Tendai Caithness Muhle, Department of Psychology, Julius Nyerere School of Social Sciences, Great Zimbabwe University, P. Bag 1235, Masvingo, Zimbabwe. E-mail address: vicladtendai@gmail.com / Tel.: +2630783488039
} 


\section{Introduction}

Single Parenting families have replaced the traditionally intact family. According to Ortese (1998), 'parents are the first point of contact with children. When both parents are present, it implies that the child would derive more care. A single parent is a parent not living with a spouse or partner'. The single parent Single-Parenthood (SP) has the entire obligation in raising children. Studies by Salami and Alawode (2000), and Bada and Ayodele (2012) asserted that 'single parenting results from divorce, separation of various kinds, having children from wedlock or death of one spouse, and leaves the role in the hands of a single parent'. Thus, society continues to grapple with the breaking down of the traditional family forming new structures that adversely affect the development of children in particular. Zirima (2012) went further asserting that divorce, poverty, urban migration, HIV/AIDS pandemic and the recent Corona virus disease (COVID-19) pandemic are contributing to the breakdown of the family. Research from the National Statistics Survey 2016 has shown that 30\% of white children, $54 \%$ black children and $38 \%$ Hispanic children live in single-parent homes. Most children from such backgrounds do not perform well academically. The intact married family delivers fundamental educational benefits to children; hence, the breakdown of such a family impacts children's achievement and attainment in school (Abudu \& Fuseini, 2014). Abudu and Fuseini (2014) went further by saying, 'When one of the parents is absent in a child's life, a gap is created as the child would lose the support that would have emanated from that parent'. Intact families play a crucial role in the socialisation of children; therefore, single parenthood has a great impact on educational outcomes.

AP is crucial in any educational setting and a necessity for future success. In this new era also, education is important for the general well-being including getting better opportunities for living. For one to make a difference, performance grades remain a top priority for educators. However, there are variables that affect the performance of learners in schools, and one such variable is single parenting. Single parenthood is now a phenomenon in Zimbabwe and worldwide, as this research will explore, but before then, it was rare or unknown. Having both parents in the home is fundamental to the academic performance (AP) of a child. As put by Uzuki and Suetomi (2015) and Zhou (2014), 'education is of great importance to every nation, attracting considerable attention to the family, community and to all tiers of the government, education is discussed, planned and processed. The distribution of academic achievement of children from single-parent families is always right-skewed because many single-parent families lack economic, interpersonal and other resources associated with children's educational outcomes'. Zirima (2012) likes to put these factors as intrinsic and extrinsic factors, generally affecting the educational achievement of children. He went further in saying children having one parent at home suffer 'double-jeopardy': the first one being the difficulties they experience in learning and the second one being the absence of one parent to support them through their challenges. The role played by parents is undoubtedly a contributing factor to the educational achievement of children. Zirima (2012) went further assessing learning disorders in children using the 'American Psychiatric Association Diagnostic and Statistical Manual of Mental Disorders (DSM-5). The DSM-5 description of learning disorders is characterised by an individual's achievement on individually administered standardised tests in reading, mathematics and spelling being substantially below that expected for age, schooling and level of intelligence'. Living in a single-parent home can make learning to read, write and do mathematics challenging and painful. Literature has revealed children from single-parent homes achieving less and getting into trouble more often than children from double parent homes (Mudhovozi, Nyanga, Kasayira \& Zirima, 2011).

Grall (2009) reported that 'globally, single-parent families are increasing rapidly. For instance, there are approximately 13.7 million single parents in the USA with more than 12 million single parents in custody of over 21.8 million children in 2009 (about $26 \%$ of children 21 years and below). This has been reported to be quite challenging, placing extraordinary demands on both the parent and the children academically. A number of divorce cases leading to single parenting have risen considerably in Europe since 1960 and most affected countries include the United Kingdom, Portugal, Denmark and Belgium'. 
Similarly, Hon and Huag (2000), in their research on students from China-Taiwan, found that 'children in single-parent families had a lower rate of attending college than those from intact families'. Tobishima 2018 has similar trends in Japan. Single mother households with children 18 years and below doubled from $3.4 \%$ in 1988 to $6.8 \%$ in 2010 and $7.9 \%$ in 2017 on divorce only. The research concluded an $80.8 \%$ single-parent household in 2017 through divorce only. Single parenting is therefore a phenomenon that is affecting all parts of the world, including Africa. In South Africa, as put by Huebsch, Banggawan and Agbisit (2013), 30\% of women in the population are single parents.

According to 'the Ghana Statistical Service (GSS)(2012),the population of Ghana aged 12 years and older constitutes $16,886,305$. Out of the total $(7,237,730), 42.9 \%$ are married, $1.9 \%$ are separated, $3.4 \%$ are divorced while $4.9 \%$ of them are widowed. This shows that in Ghana about $(1,713,743)$ that is $10.2 \%$ of the people are single parents who are separated, divorced and widowed'. It was concluded that academic prowess and SP do not positively relate. This is mainly because, as Amoakohene 2013 highlighted, 'there are some problems which are exceptional, which are only faced by single parents, which creates difficulties in raising children. These problems include bitterness towards absent spouses, loneliness, poverty and insecurity about raising children alone without help'. Salami and Alowonde (2000) showed that even in the sub-Saharan region, and in Zimbabwe, there is not much difference in patterns compared to western countries. In Zimbabwe, single parenting began as early as 1960. Most studies, such as by Jakachira (2012), focused on child-headed families and AP, and by Chinyoka etal. (2014), looked at Home Factors contributing to the AP of a girl child. Zirima (2012) looked at Absent Father Households and AP of children. Other researchers looked at the structure of the family and polygamy affecting the academic success of a child. Single parenthood, therefore, affecting the AP of pupils, is an area that is still under research in Zimbabwe. However, there is one particular research by Zirima (2012) that focused 'on single parenting on AP of children'; its population, however, concentrated on one regional area in Zimbabwe, although the results were consistent with other research findings across the world. Moreover, new family structures have also emerged within the country due to the economic, social and political hardships that the country is currently facing. This has led to broken homes and single-headed families. Recently, in the Manical and region, only Mutare, it has been published in the H-Metro (2019) newspaper article, that there are over 2,000 cases filed for divorce in a week only. Thus, many children find themselves left with a single parent.

Recent research has revealed that students from traditional families have the best AP while those from single-parent families performed poorly. They further revealed a big difference in the educational achievements of a boy and a girl child from a Single-Parent-Homes (SPH).

Abudu and Fuseini (2014) examined 'the influence of single parenthood on AP on whether AP differs between children from single-parent homes and those from two-parent homes. A crosssectional study design was used. A questionnaire aided the collection of data while secondary data on test scores were obtained from pupil's reports cards. Stratified random sampling was used to select 170 students. Data analysis involved using tabulation and $t$-test. The results showed that there is a significant difference (SD) between the AP of pupils from single-parent homes and those from double parent homes. Pupils from single-parent homes performed less than those from double-parent homes with a $t$-test of -4.770 . Moreover, the data revealed that girls performed better than boys with a $t$-test of -4.460 , both from SPH on academic achievement. The research concluded that single parenting has a negative impact on a pupil's AP, recommending teachers to give more attention to single-parent pupils'.

Tobishima S, 2018 carried a study 'on single parenthood and AP in Japan. He collected data on a 3 -year-period to assess the reading literacy, mathematical literacy and scientific literacy of students. He investigated the effects of single parenthood across the entire distribution of children's academic achievement using quantile regression techniques. About 510,000 students from 65 schools participated. A stratified random sampling procedure was used. Schools were randomly selected, and 35 students were drawn from each chosen school; results showed that the magnitude of the academic 
gap between children in single-parent and double parent families was not equal for each quantile of the conditional distribution of children's academic achievement. The negative effect of single parenting on a child's AP was more profound. Pupils from single-parent homes had a mean of 517.72 compared to 545.76 from double-parent homes. The results suggested a low achievement level of children from single-parent homes. It also suggested a low achievement level for boys than girls from single-parent homes'.

It can be argued that both parent's participation in the education of a child is fundamental to the academic success and overall functioning of that child. As put by Mwanakatwe (1968), 'parents provide financial support, emotional support and motivational support and as well facilitate resources. If one parent is absent in a child's life, many areas in that child's life are affected, including AP'. This research should be a source of concern to educators, parents and the government. Single parenting, while being a problem for the single parent, is largely a problem of the nation, as quoted by Mwanakatwe (1968), '...the future is for the young which education must mould with the highest possible degree of perfection'. An in-depth exploration of the phenomena is necessary.

\section{Objectives of the study}

1. Compare results of a Mathematical and English Language Test of learners from SPH and Double-Parent-Homes (DPH).

2. Compare the AP of male pupils and female pupils from $\mathrm{SPH}$.

3. To proffer recommendations on how children from SPH can be assisted to enhance their AP.

\section{Statement of the problem}

Students who go through the death of their parents, separation and divorce many times fail in performance and achievement. According to Grall (2009), 'children are supposed to live with both biological parents; when this fails, children do not get necessary guidance and sometimes these children become wayward by skipping or dropping out of school'. In addition, given the current hardships that Zimbabwe is going through, the schools are likely to have more pupils from SPH and little seem to have been documented on the 'influence of single parenting on pupil's AP'. In order to fill this gap and bring awareness to Zimbabwean policymakers, this study will look in to the influence of SP on pupil's AP.

\section{Hypothesis}

'There is no SD in the AP of children from SPH and those from DPH'.

HO: 'There is no significant relationship between single parenting and pupil's AP at Mutare Junior School'.

HO: 'There is no SD in the AP of male pupils to female pupils from SPH at Mutare Junior School'.

\section{Methodology}

\subsection{Design}

The design for the study is a 'quantitative cross-sectional study design'. Kumar (1999) stated, 'A cross-sectional study design is best suited for finding out the prevalence of a phenomenon, situation, problem or attitude by taking a cross-section of the population. This design is appropriate for a study that involves collecting data from pupils who live with a single parent and those who live with double parents at only one point'. The design therefore would give explicitly detailed findings of the research. 


\subsection{Population}

As put by Kumar (1999), 'A target population is the larger group which one aspires to apply findings to'. The total target population consisted of 100 pupils $(n=100)$. The population consisted of students from Grade 6 and 7 classes only. These students were purposely selected from each of the five different classes for each grade at Mutare Junior School. These were children from SPH and from DPH. Of the 100 students, 50 were Grade 6 students having 25 from SPH and 25 from DPH. The other 50 were Grade 7 students having 25 from SPH and 25 from DPH.

\subsection{Sample and sampling technique}

'Stratified Random sampling' was employed for the participant's selection from the population. Eighty participants (sample) were chosen from the population using the Krejcie and Morgan (1970). The sample was first graded into 40 pupils from SPH and 40 from DPH. They were further ranked according to their sex before 'simple random selection' into 20 females and 20 males from SPH, making sure both sexes form the sample. 'Simple random sampling' was applied to choose participants from DPH, 22 females and 18 males ensuring that each child of the population had the same chance of being selected for the sample.

\subsection{Data collection instrument}

A Wide Range Achievement Test Level 1(WRAT-1) instrument was used on the sampled pupils. As put by Kumar (1999), 'The WRAT-1 measures an individual's ability to read words, spell and compute solutions to math problems. The test is appropriate for ages from 5-94 years. The instrument provides the foundation from which to further assess academic skill competences'. It is a test widely used in Schools Psychological Services of Zimbabwe. It consists of the English Spelling subset, Reading subset and Math computation subset.

\subsubsection{Validity and reliability of WRAT-1}

The WRAT-1 has gone through a series of testing for validity and reliability. It has split-half reliabilities of 0.97 for reading, 0.96 for spelling and 0.94 for arithmetic. These results indicate the WRAT-1 is overall excellent and reliable.

\subsection{Document analysis}

The researcher used an End of First Term, March 2020, Examination Test (a test conducted by the school for the purpose of grading to the best class). Results of Mathematics and English Tests of the sample comprised the data from the reports cards of the students. Calculating the average of the two test scores for each subject is to avoid skewed data as differences in performance exist.

\section{Data analyses}

Tables have been used to quantify the data. The different APs and gender differences of pupils from $\mathrm{SPH}$ and DPH were analysed using tables. The $t$-test statistical highlighted if 'SDs' prevailed in APs of male vs. female subjects from SPH.

\section{Procedure}

The researcher obtained written approval from the headmaster of the school to conduct a study following letters from the Great Zimbabwe University submitted to the school prior to data collection. Rapport was established for informed consent of the respondents about the purpose of the study 
which was for academic purposes and recommendations to the school. Beneficence was observed, and as well since data were collected in the early days of the COVID-19.

\section{Presentation of results}

\subsection{Influence of SP on AP}

\subsubsection{Document analysis}

English Test Results

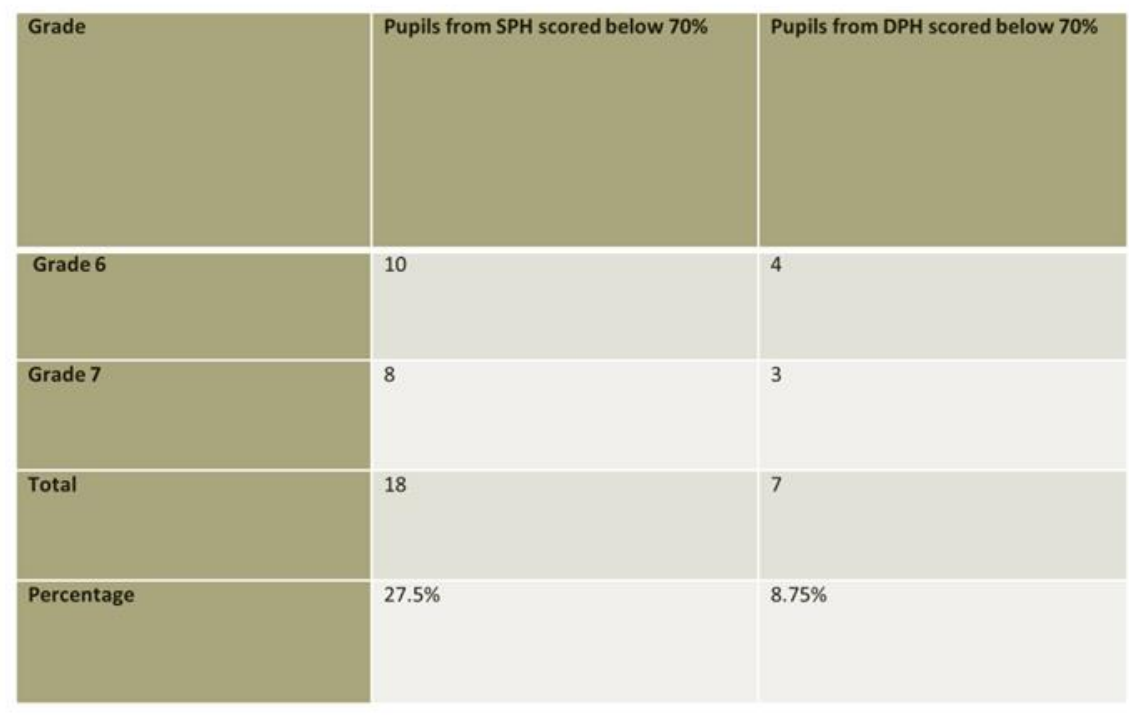

Mathematics Test Result

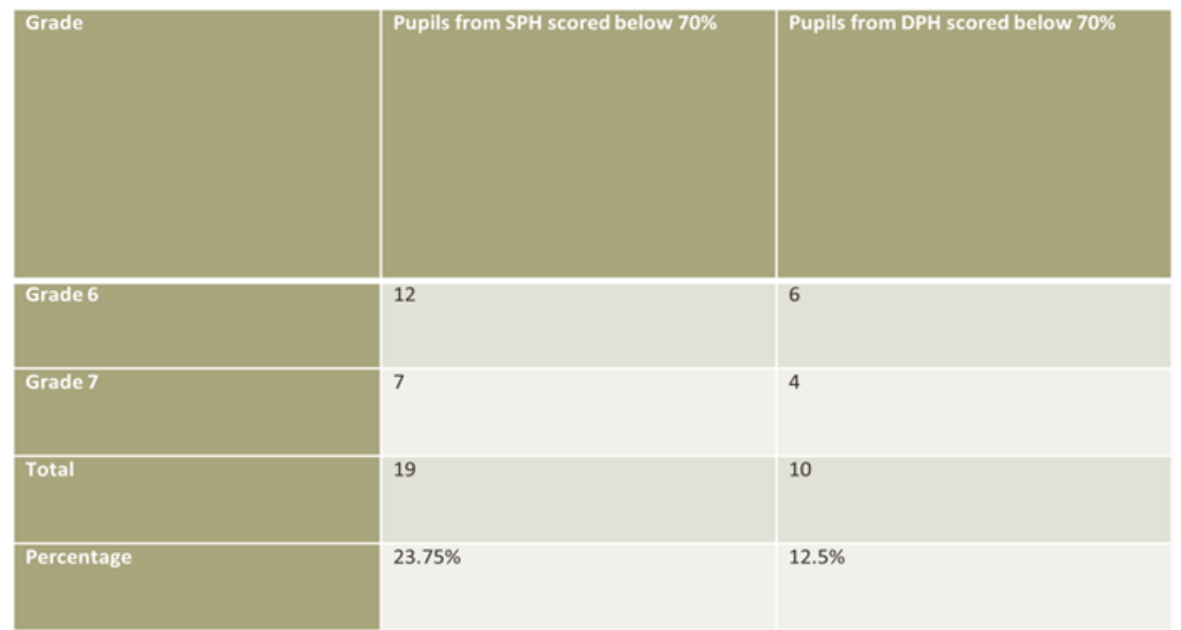

From the End of First Term English Test carried out at the school, 18 students (grades 6 and 7), out of 40 from SPH, scored below the $70 \%$ grading system of the school, which is $27.5 \%$ of the entire sample. This reveals a marked difference with their counterparts from DPH, who have 7 participants out of 40 only scoring below $70 \%$, thus an $8.75 \%$ of the entire sample. Similar results are found on the Mathematical Test taken at the school. Nineteen students out of 40 students both grades and from $\mathrm{SPH}$ scored below the $70 \%$ rating system of the school, with a $23.75 \%$.In addition, the difference is 
sharp compared with students from DPH where 10 out of 40 scored below the averaged $70 \%$ rating system.

Thus, children from SPH performed less academically as compared to their counterparts from DPH. From these results, single parenting negatively influences AP of pupils as revealed by the marked gap in scores. It should, however, be highlighted that not all children from SPH perform poorly as evidenced on the table and as well that not all children from intact families do well in school as indicated above.

\subsubsection{Wide Range Achievement Test Level 1 (WRAT-1)}

Following the administration of the WRAT-1 on the respondents, a discrepancy of grades was noted among the respondents. The WRAT-1 is an achievement test that highlights a discrepancy of a student's actual grade and that student's achievement grade. For instance, a pupil in grade 7 can have an achievement level of a grade 4 student, having a discrepancy of three grades. The researcher used a discrepancy level of more than two grades on the sample.

Moreover, the WRAT-1 highlighted a discrepancy in the Mental Ability of some respondents in relation to their Chronological Age. For example, a 12-year-old pupil in grade 7 can score at grade 2 level student who is 7 years, thus a discrepancy of 5 years between the mental ability and Chronological age. The researcher used a discrepancy level of more than 3 years which is truly indicative that a child is being affected in some areas of life. Tables below indicate these notions.

\section{Discrepancy of more than two grades}

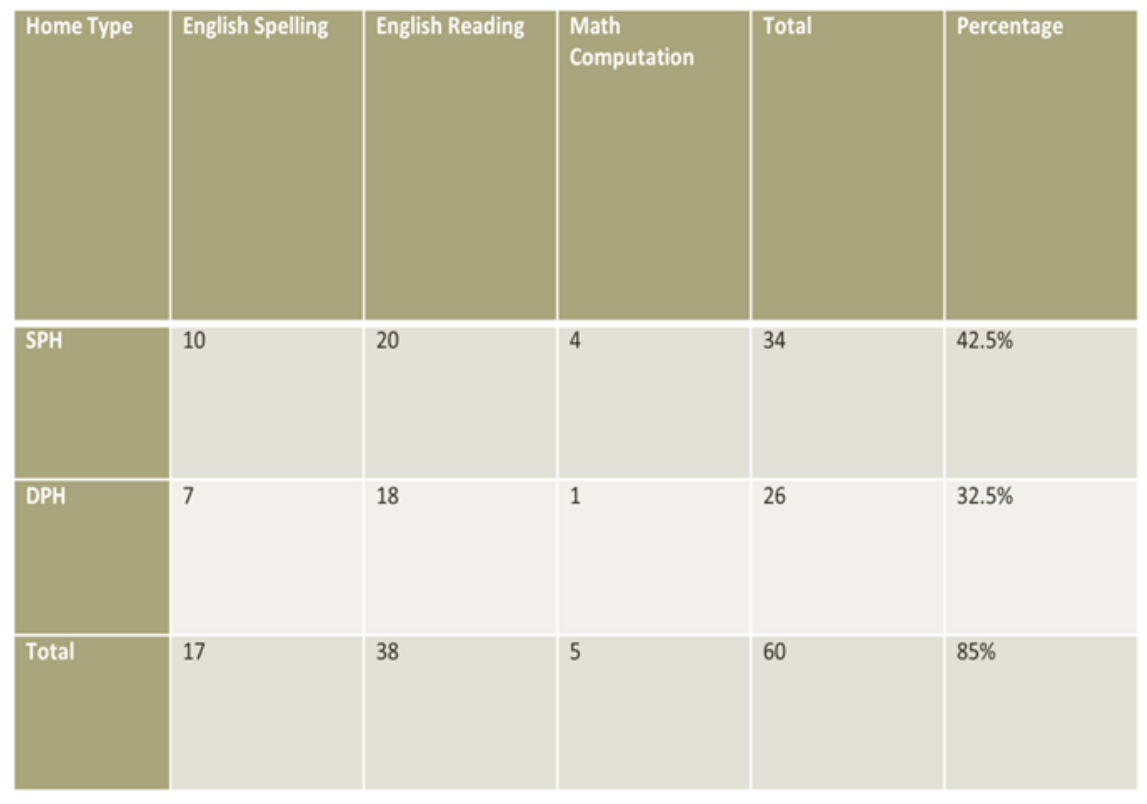

The table indicates that $42.5 \%$ of test-takers from SPH had a discrepancy of more than two grades on their WRAT-1. Thus, grade 6students would achieve at the level of grade 4students or below in reading, spelling and maths sums. Most test-takers had difficulties in reading leading to elevated figures. The discrepancy level from SPH respondents was too high as compared to their counterparts from DPH. Their discrepancy level was lower on all the WRAT-1 subsets, i.e., on maths, reading and spelling with a $32.5 \%$. This concludes that students from DPH had a better performance than students from SPH, indicating that SP does affect a child's academic capability. These results support other research that has been carried out on the similar topic with Huebsch et al.(2013) implying that 'a child's well-being is fully functional when the father and mother are present in the life of a child, giving 
emotional, psychological, financial and mental support including academic support'. Family Systems Theory views the family as a system, if one element is missing the whole system is affected in every area of functioning, thus including a child's AP.

Discrepancy level of more than 3 years of the Chronological age and mental ability of a student.

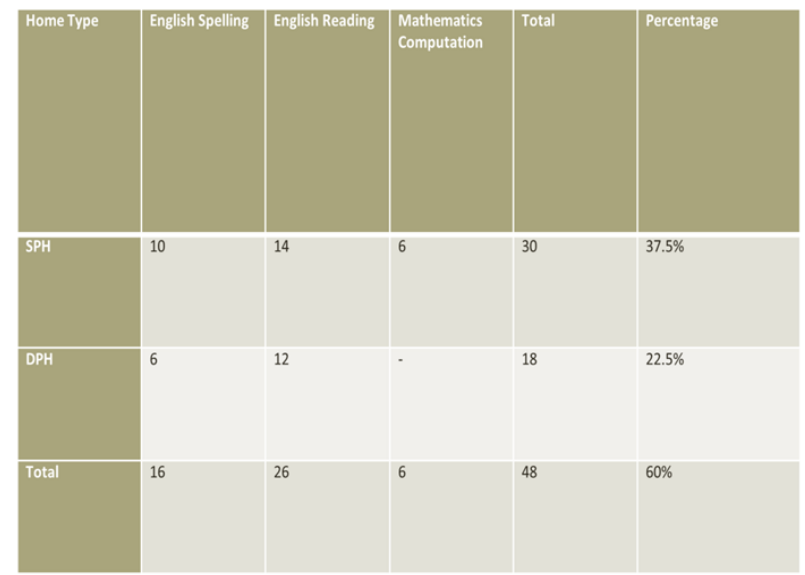

The table above shows that 48 students of the total sample of 80 students had a discrepancy of more than 3 years in their chronological age and mental ability. Of these 48 participants, 30 of them were from SPH, with a $37.5 \%$ showing greatly how SP affects AP. This is because only 18 students from DPH of the entire sample were affected. To add water, no student from DPH showed a mathematical discrepancy level of mental ability to chronological age compared to 6 students from SPH. The statistics above support the fact that single parenting influences A Pas more students from SPH are being affected than those from DPH with $22.5 \%$. These results augur well with studies that concluded AP heavily depends on both parents being involved in academic activities of a child for mental age development and academic success.

\subsection{Gender: does single parenting affect a male and female child equally the same}

Researchers have found a gap between the achievement levels of male to female students from SPH. Most researchers have found that females perform better than males while this research found boys performing better. The researcher in this study was interested to validate this notion and see if it can be applied in the area the study was carried out. The WRAT-1 was used.

\section{Discrepancy of more than 2 grades between boys and girls from SPH}

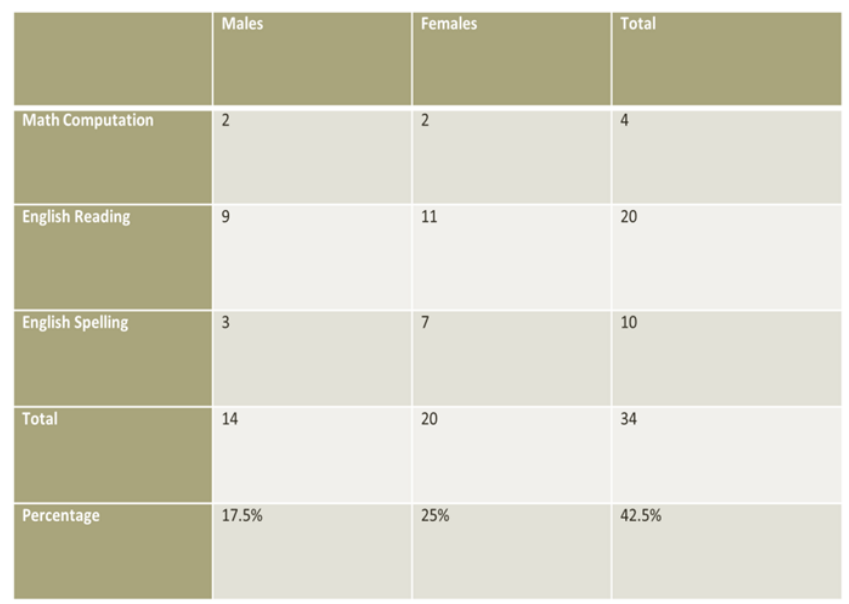


From the above table, it can be concluded that more girls are being affected by single SP than boys. In areas of mathematics, they were equally standing. Nine boys compared to 11 girls were affected by single parenting. Three boys were affected in spelling compared to seven girls. Thus, 20 girls had a discrepancy of more than 2 years compared to 14 boys. This research agrees with few studies such as by Amato et al.(2000), who argued that at the primary level of education, SP can affect both a boy and girl child equally the same as evidenced on the abovementioned math computation table. Moreover, girls can be affected more due to the heavy responsibilities of chores given especially in the African community, as the parent will be out of home working to support the family. SP, therefore, affects more the girl child by $25 \%$ than it does a boy child by $17.5 \%$. Boys perform better than girls from SPH.

Discrepancy of more than 3 years in Chronological Age and mental ability of students from SPH

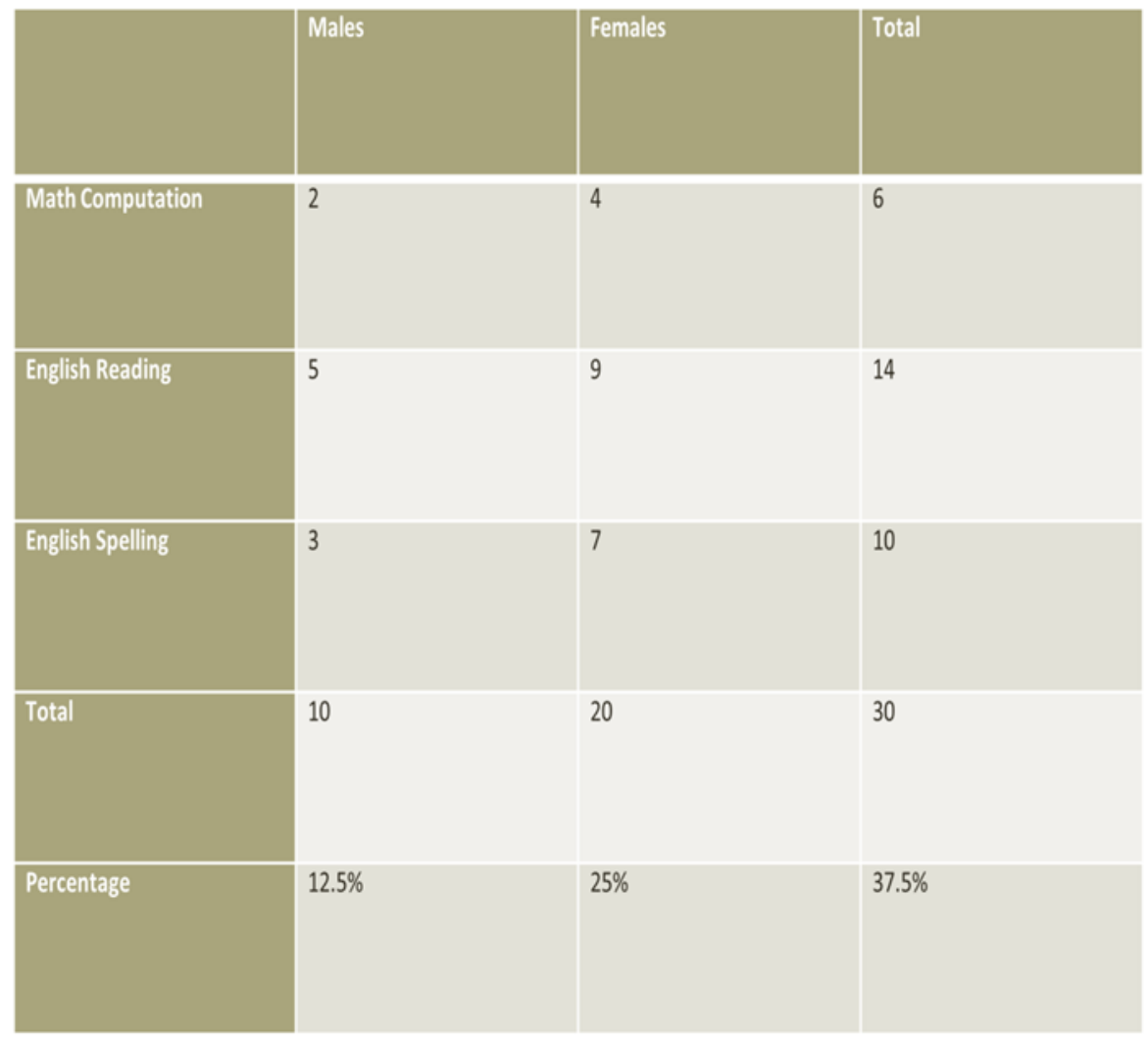

From the abovementioned table, $25 \%$ of females are affected by single parenthood as compared to $12.5 \%$ of males. Overly, on the WRAT-1, more girls showed a great discrepancy of chronological age to mental ability than boys did. Thus, it can be safely concluded given such statistics that boys perform better than girls from SPH. Single parenthood affects more the girl child, 20 female participants, than it does to a boy child, 10 male participants.

\subsection{Hypothesis testing}

The following $\mathrm{HO}$ is tested.

HO: 'There is no significant relationship between single parenting and pupil's AP at Mutare Junior School'.

HO: 'There is no SD in the AP of male pupils to female pupils from SPH at Mutare Junior School'. 


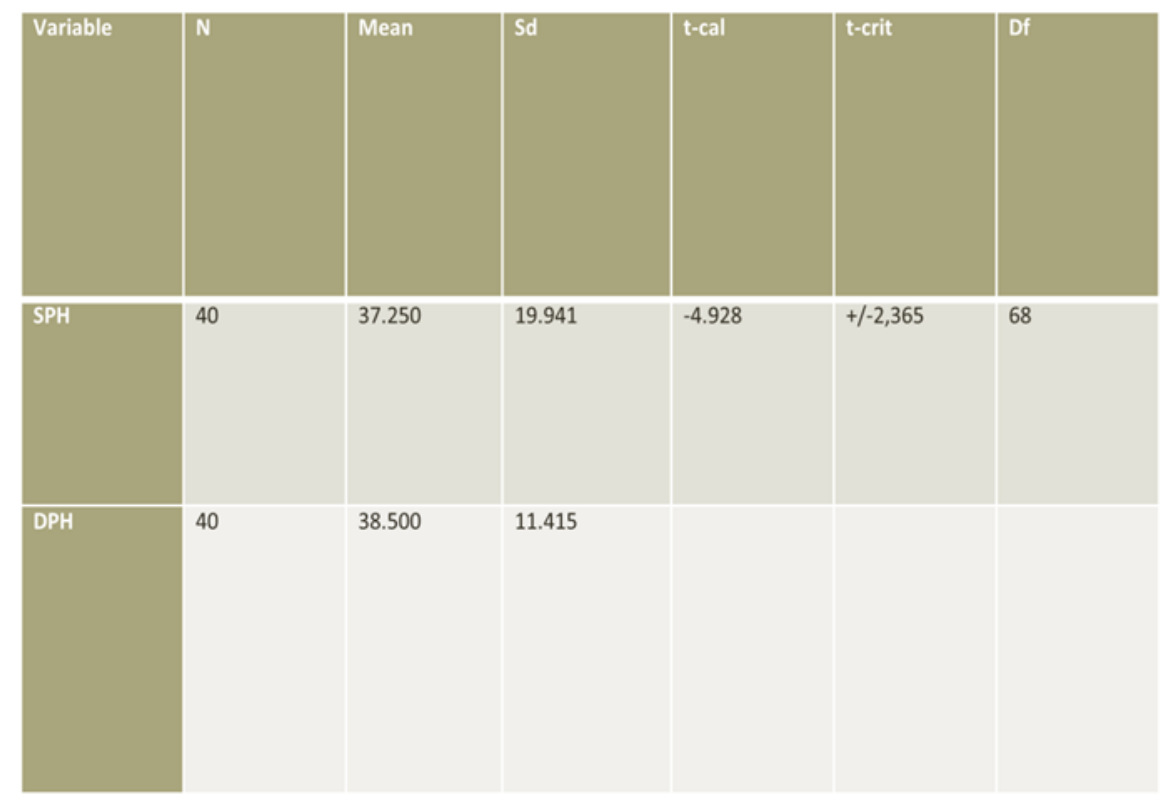

(a) t-test difference of AP of pupils from SPH and those from DPH

A 'significance level of $0.05^{\prime}$ is given. The table above shows a t-cal of -4.928 and the t-crit is $+/-2.365$. It is clear from the results that $t$-cal falls in the rejection region of the Ho. Hence, Ho is rejected and $\mathrm{H} 1$ accepted, concluding a significant relationship between SP and the AP of pupils with $\mathrm{SP}$ affecting AP in a non positive way. A mean score value of 37.250 from SPH and38.500 from DPH shows that pupils from DPH have a higher mean score depicting a better AP compared to those from $\mathrm{SPH}$. These findings agree with (Pong, Dronkers \& Hampden-Thompson, 2003) findings that children from DPH perform better.

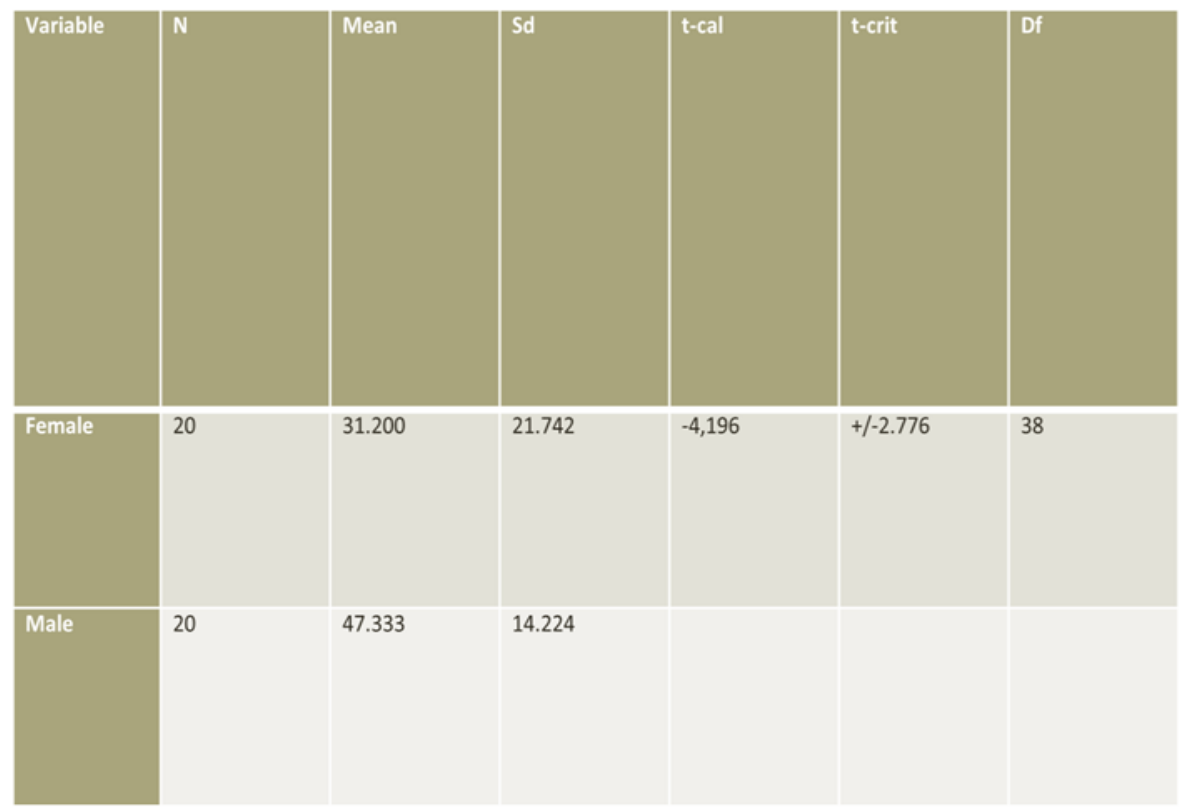

(b) t-statistical test of difference on AP of students (male and female) from SPH. 
The results denote that the $t$-cal of -4.299 falls in the rejection region with a significance level of 0.05 . This clearly signifies that $\mathrm{HO}$ is rejected and $\mathrm{H} 1$ accepted. Hence, we find a SD in the AP of female to male pupils from SPH. The mean score values show that male pupils (47.33) from SPH perform better than female pupils (31.200). These findings are in line with Salami and Alawode's (2000) research which 'discovered SDs in AP of the male and female pupils from SPH, with girls performing better than boys'. The reasons why in this research boys performed better might include the study population, differences in parental participation in children school work and sample sex composition.

\section{Discussion}

The researcher sought to test for any significant relationship between SP and pupil's AP. The first findings of the End of First Term English Test carried out at the school showed 18 out of 40 students from $\mathrm{SPH}$, that is, $27.5 \%$ scored below the $70 \%$ grading system of the school. In contrast, their counterparts from DPH were only 7 out of 40 with an $8.75 \%$ scoring below the $70 \%$ grading system. The same scenario was found on the End of First Term Mathematics Test with $23.75 \%$ from SPH compared to $12.5 \%$ from DPH. These results indicate SDs in academic achievement between pupils from SPH and DPH with those from SPH performing less. These findings concur with other researches done on the same topic. For instance, Abudu and Fuseini (2014) showed 'a SD between the AP of pupils from SPH and DPH using tests scores obtained from pupils report cards'. The data analysis which was done using cross-tabulation from that research highlighted that SP negatively had an impact on academic success. Moreover, the gap in scores in this research between the variables is consistent with findings by Zhou (2014), Covagh and Fom by (2012) who concluded a low achievement of students from SPH and a better achievement of students from DPH. As alluded by Zhou (2012), 'SP has a mutual relation with school failure having cases of pregnancies, delinquency, drug use and poverty amongst others'. In short, there is a significant relationship between SP and pupil's AP as children from SPH perform poorly than those from DPH.

Following the WRAT-1 administration, $42.5 \%$ of respondents from SPH had a discrepancy level of more than two grades in their achievement raw scores as compared to $32.5 \%$ of respondents from $\mathrm{DPH}$. This concludes that pupils from SPH perform less than those from DPH on reading, spelling and mathematical computations, indicating single parenting does negatively influence the AP of a child. In addition, $37.5 \%$ of students from SPH had a discrepancy level of more than 3 years in their chronological age to mental ability as compared to $22.5 \%$ from $\mathrm{DPH}$. This gap of difference greatly shows a significant relationship of SP to poor AP of a child. These findings agree with a research by Pong et al.(2003), who used multilevel modelling to show that 'a high proportion of American children from SPH perform poorly on mathematics, reading and spelling achievement'. A similar research by Tobishima (2018) concluded similar results 'of poor reading literacy, mathematical literacy and scientific literacy on children from single-parent families in Japan'. AP heavily depends on both parents being available and there in the life of a child. This coincides with the Family Systems Theory by Salvador Munichin et al. (1960), which postulates the father, mother and child as a system interdependent on each other, constituting a whole. Scholars of the theory argue, once that wholeness is broken, the traditional family system is broken, new family structures emerge which come with inherent problems that affect a child's AP. It is therefore conclusive enough to say there is a significant relationship between SP and a pupil's AP, with children from SPH showing less achievement.

The $t$-test carried out by the researcher with a t-calculated value of -4.928 falling in the rejection region led the researcher to reject the $\mathrm{HO}$ and conclude to the fact that there is a significant relationship between SP and pupil's AP $(\mathrm{H} 1)$. Single parenting does negatively impact on a child's favourable outcome in education. Moreover, the high mean value of $38.500 \mathrm{from} \mathrm{DPH}$ as compared to a low mean value of 37.250 from SPH is indicative of the unlike differences in school achievement of test-takers, having DPH students performing better. Conclusively, the $\mathrm{HO}$ is rejected and $\mathrm{H} 1$ accepted. These results correlate with Chopra and Kalita (2000), who carried out a cross-sectional similar study 
on 100 elementary students. The study accepted $\mathrm{H} 1$ with a $t$-test value of -4.843 . Moreover, results by Mwanaidi, Ali Adan and Karama (2018) with the same design had a $t$-test of -4.770 which led him to reject the null hypothesis and both studies coming to the conclusion that single parenthood is negatively linked to AP. In addition, this research's findings of the differences in the mean value of the two groups are in line with recent research by Tobishima (2018), who obtained different mean values of pupils from SPH (517.72 mean) and DPH (545.76). This suggests low achievement level of children from SPH, more likely dropping out of school due to strained financial resources, less time for homework, less parental control leading to lower academic achievement. Zirima (2012) concluded 'single parenting negatively affects the self-esteem of children leading to a drop out in AP, juvenile delinquency and psychological abuse. No-matter which parent is missing, children from single-parent families generally find it more difficult to connect with school'.

The researcher also tested for an SD in the AP of male pupils to female pupils. FollowingWRAT-1 administration, $25 \%$ of female students from SPH had a discrepancy of more than two grades as compared to $17.5 \%$ of male students from a similar home. These findings revealed a SD on AP pupils from SPH with boys performing better than girls. Thus, single parenting affects more a girl child than it does a boy child. To add water, $25 \%$ of these females had a discrepancy level of more than 3years in their chronological age to mental ability in comparison and to a difference of $12.5 \%$ discrepancy level of the male student. Having come out with such statistics, it can be safely concluded that a SD exists on AP of a boy and a girl student from SPH. H1 is accepted, and HOis rejected. Moreover, the results in this paper indicated that the male students had a better performance than the female students, concluding SP affects the girl child more than it affects the male child. This might be a result of the many tasks placed upon a girl child, then on the boy child, especially in the African context. This research's findings are in contradiction with many of the existing literature. Findings by Uzukiand Suetomi (2015), Bada and Ayodele (2012), Anyakoha (2016), Salami and Alawode (2000) and Tobishima (2018) showed girls from SPH performing better than boys, concluding a SD in the AP with boys being affected by single parenthood than girls, highlighting the delayed development that is intrinsic within a boy child. Research by Farooq, Chaudhry, Shafiq and Berhanu (2011), concluded the boy child performs less than a girl child in a similar home because of a loss of sense of well-being especially if the single parent is a mother and not a father. This comes to Bandura's Social Learning Theory where the father acts as a role model to the boy child. Given that many single-parent homes are mother-headed, a boy child is left with no role model resulting in role confusion, leaving a vacuum difficult to fill and ultimately, academic failure (Zirima, 2012).This research has therefore managed to conclude that even boys can perform better than girls, both from single-parent household. The differences in researches might be due to other factors at play which must be looked into.

Denoting from the $t$-test carried out, with a t-calculated of -4.299 , which is falling in the rejection region, the $\mathrm{HO}$ was safely rejected and the $\mathrm{H} 1$ accepted, stating a SD on AP of a boy to a girl pupil from $\mathrm{SPH}$. The difference in the mean values indicates males perform better with a mean value of 47.333 , than females with a mean value of 31.200 . These findings concur with other findings that have been presented in chapter 2 literature review of this research. For instance Mandara and Murray (2006), Lawal and Adediran (2007) and Uwaifo (2008), these findings concluded differences in AP of a boy to a girl child from SPH with girls performing better than boys.

This paper seeks to highlight that SP is not an exclusive prognosis of school failure for children. According to Zirima (2012) who carried similar studies in Zimbabwe, 'there are many risks and protective factors that interplay to encourage a child's academic success or contribute to a child's poor school performance. The difference therefore in the mean level of academic achievement does not necessarily imply reducing the educational inequalities associated with single-parent homes. Academic achievement testing also needs to focus on the entire distribution of children's academic achievement, not only on averaged test scores'.

By applying the WRAT- 1 and $t$-test, this paper adds to an understanding of the connection between SP and pupil's AP. More investigations are needed to understand why and how being brought up with 
a single parent affects AP, 'examining effects of the economy, cultural and interpersonal availability of resources within the t-statistics, distinguishing widowed and divorced single-parent homes' as put by Zirima (2012).

\section{Conclusions}

This study revealed that single parenting is closely related to the AP of a child. Children who come from SPH have been found to perform poorly on reading literacy, spelling literacy and mathematical computation. This was found to be different with children from DPH whose performance was better. The major conclusion was that single parenting negatively influences the AP of a child. The WRAT-1 achievement scores, the $t$-test values, the mean score values and school tests all favoured children from DPH, with an outstanding performance and children from SPH performing poorly on the same tests and below an expected range. Related literature to the study all had the same conclusions and gave many reasons to explain this wide gap of achievement between the two groups. These included financial strain on the single parent, less parental control, less attention by the parent on a child's schoolwork, double responsibilities placed on the single parent and less study time given by the child among others. This was shown to have led to poor AP on the part of a child.

This study also showed that there is an academic difference between a boy and a girl child from single-parent homes. This augured-well with existing literature that found differences as well on the gender concept. However, this study found boys performing better than girls on all the standardised tests administered. The boys had less discrepancy in grades to achievement, less discrepancy of chronological age to mental ability, scored higher than girls on their end of term tests and had a higher mean score value on the $t$-test employed. Thus, it was concluded that single parenting affects the girl child more than it does the boy child. This conclusion however was not consistent with existing literature, which, although found differences in scores between the girl and boy child, found girls to perform better than boys. The main suggestion of such literature differences was that boys have a high level of role confusion that affects their schoolwork and lead them into delinquent behaviours as most SPH are headed by women, with the fathers remarrying and most children comfortable living with their mothers. Single parenthood, therefore, as put by Huebsch et al. (2013), 'continues to be a reality for many adults and almost $50 \%$ of children born today will spend significant time living with only one parent'.

\section{Recommendations}

- The government should include in their legislation policies that assist struggling single parents sustain their children, as well as policies that will govern these children's education.

- The Ministry of Education should work well with the government in setting educational policies that facilitate a better educational system for a child that comes from SPH, moreover, making sure these educational policies are being maintained in all schools.

- Schools should set up 'Guidance and Counselling Platforms' helping children with Mental Health First Aid Wellbeing in the areas of child anxiety, depression, truancy, grief, trauma and personality problems so that the children can cope with school work and measure up at an equal footing with those from DPH.

- Schools should engage support groups for single mothers so that they are provided psychosocial education on parental role awareness, sharing information and experiences improving their situation, starting income-generating programmes to cater well for their children.

- The researcher suggests further in-depth research on this study in areas of type of single parent, level of parental involvement, grade to age of child and impact of schools guidance and counselling platforms to the AP of children from SPH. 


\section{References}

Abudu, A. M. \& Fuseini, M. N. (2014). Influence of single parenting on students' academic performance in basic schools in the WA Municipality. International Journal of Education and Development, 1(2), 85-94.

Anyakoha, C. I. (2016). Single parenting as correlate of academic performance of students in Unity Secondary School in South East Geopolitical Zone in Nigeria. International Journal Technology and Inclusive Education, 5(2), 837-841.

Bandura, A. Social/Learning/theory.Retrieved/from www.Isrhs.net/sites/kleina/files/2012/11/sociallearning theory.pdf

Farooq, M. S., Chaudhry, A. H., Shafiq, M. \& Berhanu, G. (2011). Factors affecting students' quality of academic performance: a case of secondary school level. Journal of Quality and Technology Management, 7(2), 01-14.

Ghana Statistical Service (GSS). (2012). 2010 population and housing census-summary report of final results. Accra, Ghana: GSS.

Grall, T. S. (2009). Custodial mothers and fathers and their child support. Washington, DC: US Census Bureau.

H-Metro. (2019). Newspaper article. Mutare, Zimbabwe: Manica Post Newspaper.

Huebsch, L. G., Banggawan, M. L. \& Agbisit, I. (2013). Parents' role in enhancing the academic performance of students in the study of mathematics in Tabuk City, Philippines. International Journal of Advanced Research in Management and Social Sciences, 2(8).

Krejcie, R. V. \& Morgan, D. W. (1970). Determining sample size for research activities. Educational and Psychological Measurement, 30, 607-610.

Kumar, R. (1999). Research methodology: a step-by-step guide for beginners. New Delhi, India: Sage Publications.

Mandara, J. \& Murray, C. (2006). Father's absence and African American adolescent drug use. Journal of Divorce and Remarriage, 46, 1-12.

Mudhovozi, P., Nyanga, T., Kasayira, J. \& Zirima, H. (2011). Youth culture: a melting pot in Zimbabwe. Journal of Sustainable Development in Africa, 13(2), 352-365.

Mwanaidi, A., Ali Adan, A. \& Karama, M. (2018). The influence of single motherhood on the academic performance of children in Islamic faith-based schools, Mombasa county, Kenya. African Journal of Education and Practice, 3(3), 33-50.

Mwanakatwe, L. M. (1968). Growth of education in Zambia since independence. Nairobi, Kenya: Oxford University Press.

National Centre for Educational Statistics. (2008). US Journal of Educational Research.

Pong, S., Dronkers, J. \& Hampden-Thompson, G. (2003). Family policies and children's school achievement in single- versus two-parent families. Journal of Marriage and Family, 65(3), 681-699.

Salami, S. O. \& Alawode, E. A. (2000). Influence of single-parenting on the academic achievement of adolescents in secondary schools: implications for counselling. Ibadan, Nigeria: University of Ibadan.

Uwaifo, V. O. (2008). The effects of family structure and parenthood on the academic performance of Nigerian University students. Study Home Community Science, 2(2), 121-124.

Uzuki, Y. \& Suetomi, K. (2015). The effects of childhood poverty on academic achievement and study habits. NIER, Research Bulletin Japan, 145, 125-140.

Zhou, Y. (2014). Single Mothers in Japan: attempt to balance work care work-care and exit poverty. Tokyo, Japan.

Zirima, H. (2012). Double jeopardy: the psycho-educational effects of absent parenting on children with specific learning disabilities. Boca Raton, FL: Universal Publishers Florida (e-book). 